This item was submitted to Loughborough's Research Repository by the author.

Items in Figshare are protected by copyright, with all rights reserved, unless otherwise indicated.

\title{
Membrane fouling prevention in crossflow microfiltration by the use of electric fields
}

PLEASE CITE THE PUBLISHED VERSION

PUBLISHER

(c) Elsevier / Pergamon Journals Ltd.

VERSION

AM (Accepted Manuscript)

LICENCE

CC BY-NC-ND 4.0

\section{REPOSITORY RECORD}

Wakeman, Richard J., and E.S. Tarleton. 2009. "Membrane Fouling Prevention in Crossflow Microfiltration by the Use of Electric Fields". figshare. https://hdl.handle.net/2134/5328. 
This item was submitted to Loughborough's Institutional Repository (https://dspace.lboro.ac.uk/) by the author and is made available under the following Creative Commons Licence conditions.

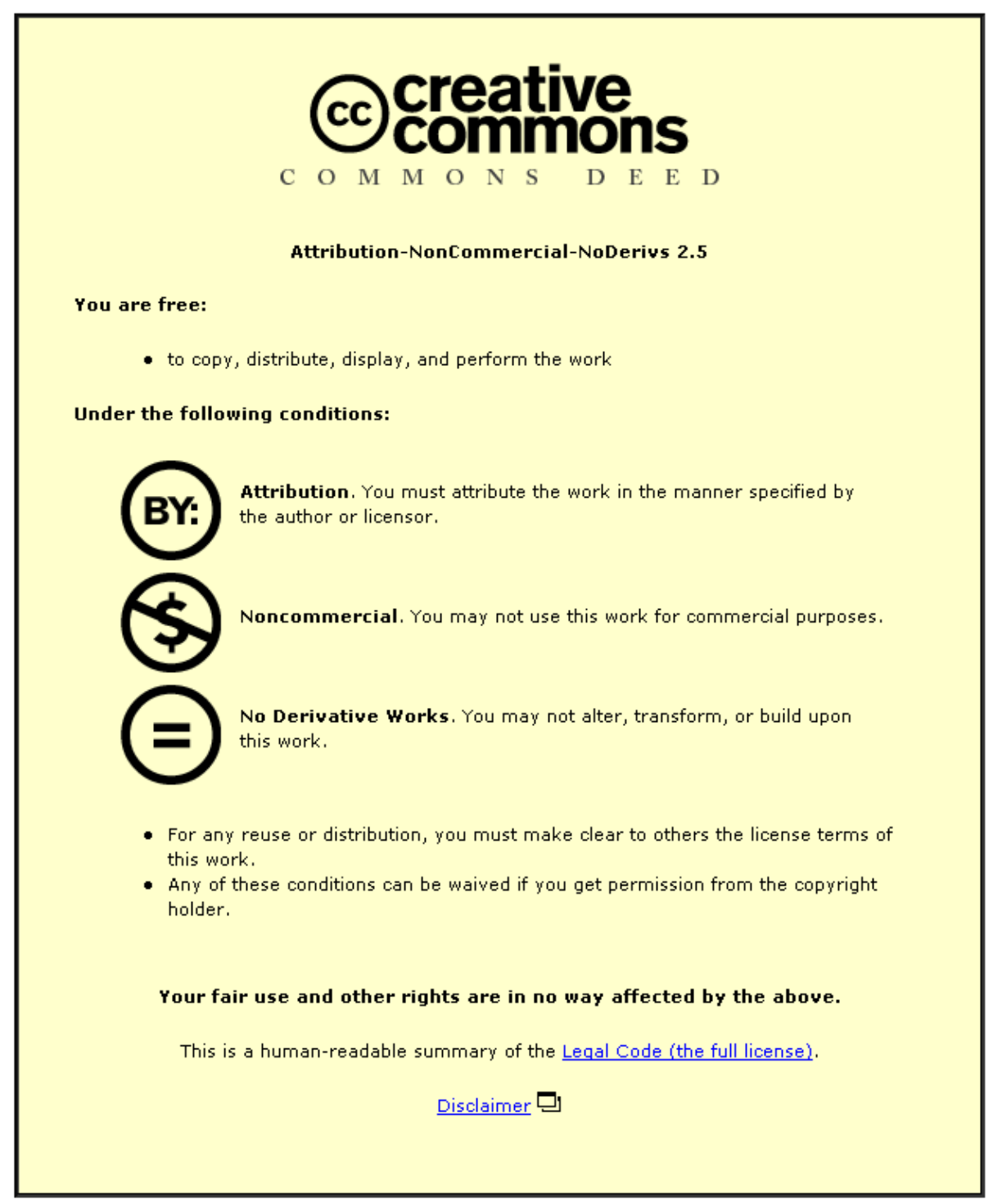

For the full text of this licence, please go to: http://creativecommons.org/licenses/by-nc-nd/2.5/ 


\title{
MEMBRANE FOULING PREVENTION IN CROSSFLOW MICROFILTRATION BY THE USE OF ELECTRIC FIELDS
}

\author{
R.J. Wakeman and E.S. Tarleton (e.s.tarleton@lboro.ac.uk) \\ Dept. Chemical Engineering, University of Exeter, Exeter, EX4 4QF, UK.
}

\begin{abstract}
From an analysis of fluid velocity and electric field profiles the trajectory of particles through crossflow microfiltration units has been calculated. A tubular geometry filter leads to the most effective use of electrical power, when it is used as an aid to prevent membrane fouling. Results for plate, tubular and multitube filters are given. Some experimental data from a tubular filter are presented, which demonstrate typical effects of the important parameters.
\end{abstract}

\section{INTRODUCTION}

The separation of fine particle species and macromolecules from dilute suspension is a common requirement in many industries, and can be particularly difficult to achieve by conventional filtration techniques. Conventional filtration of such suspensions culminates in the 'blinding' of the filter media or in the formation of filter cakes with low permeabilities, and low permeation rates ensue. In an attempt to overcome such problems two forms of crossflow filtration have been developed. Ultrafiltration (UF) systems utilise a high velocity flow, parallel to a semi-permeable polymeric membrane, to help prevent 'particulate' deposition. The asymmetric membranes used in such systems have pore sizes of the order $0.02 \mu \mathrm{m}$, which for many applications can mean filtering to finer particle sizes than necessary. Subsequently, crossflow microfiltration (CFM) was developed which utilises a similar operating principle to UF but employs membranes with pore sizes of $0.1-1 \mu \mathrm{m}$. The advantages of CFM over UF are the superior filtrate flux performance and increased robustness of the filter medium, although macromolecules and finer particles may pass into the filtrate stream. The geometric form of such filters is either 'plate and frame' or tubular, the latter consisting of a filter mounted centrally inside a solid tube with the process suspension pumped into the annular space.

Whilst crossflow filtration was originally developed to achieve separation with no filter cake formation, this situation is not usually realised in practice. The convective flow toward the membrane coupled with particle diffusion can cause an accumulation of particles at the membrane surface. If the solute concentration at the septum rises sufficiently a gel/cake may form. This membrane fouling process is termed 'particle polarisation' and is widely recognised as being responsible for the loss of performance in CFM and UF operations ${ }^{1}$. If the membrane blinds sufficiently it may be necessary to backflush the filter to remove some of the deposited cake and restore the initial filtration rate.

In recent years there has been an upsurge in research investigating the use of electric fields to reduce membrane fouling rates. Electric fields have been utilised in both deadend ${ }^{2-4}$ and crossflow filtration ${ }^{5-7}$ with many authors proposing the existence of a critical electric field strength. If this potential gradient is achieved then no particles from the process suspension can accumulate at the filtering surface. This mode of operation will cause a slurry to be thickened without the formation of a filter cake, and in theory no membrane fouling would occur. The application of a suitably polarised electric field primarily reduces filter cake formation by electrophoretic motion of the particles away from the membrane. Presented in this paper are both experimental and theoretical results which analyse the processes occurring during electrically aided CFM. The investigation involves using DC electric fields to reduce 
membrane fouling rates and theoretical calculations to evaluate the conditions required to prevent fouling.

\section{TUBULAR VS. PLATE CROSSFLOW ELECTROFILTERS}

The motion of a particle suspended in a liquid that flows through a channel with a porous wall is largely influenced by the fluid velocity profiles established. If a DC electric field is also applied across the flow space the particle motion may be further affected, particularly when the particle is smaller than about 5-10 $\mu \mathrm{m}$. The relative magnitude of the two parameters will determine the trajectory of a spherical particle introduced at one end of a separator ${ }^{10}$.

Shown in Figure 1 is a schematic diagram of the space between two solid walls, one being porous. The flow of fluid is assumed to be describable by the Navier-Stokes equations. Assuming that the flow is fully developed and laminar, that the permeate flux is constant along the separator, and that the pressure gradient normal to the porous surface is negligible, the Navier-Stokes equations may be written for a tubular geometry filter as:

$$
\begin{aligned}
& \frac{\partial^{2} v_{r}}{\partial r^{2}}+\frac{\partial v_{r}}{\partial r}\left(\frac{1}{r}-\frac{v_{r}}{v_{f}}\right)-\frac{r_{r}}{r^{2}}=0 \\
& \frac{\partial^{2} v_{z}}{\partial r^{2}}+\frac{1}{r} \frac{\partial v_{z}}{\partial r}=\frac{v_{r}}{v} \frac{\partial v_{z}}{\partial r}+\frac{1}{v}\left(\frac{1}{\rho} \frac{\partial p}{\partial z}-g\right)
\end{aligned}
$$

where $v_{r}$ and $v_{z}$ are the radial and axial fluid velocity components. For the channel geometry shown in Figure 2 these are solved subject to the boundary conditions

$$
\begin{array}{lll}
r=r_{i} & v_{r}=v_{w} & v_{z}=0 \\
r=r_{0} & v_{r}=0 & v_{z}=0
\end{array}
$$

to give the radial and axial fluid velocity distributions, assuming that no slip of fluid occurs at the septum surface.

When the volume between two conducting electrodes is filled by a suspension the potential $(\varphi)$ distribution is described by Laplace's equation:

$$
\nabla^{2} \varphi=0
$$

The exact solution to this equation can be differentiated to give the field strength distributions between two concentric cylinders:

$$
E=\frac{\left(\varphi_{o}-\varphi_{i}\right)}{r \log _{\mathrm{e}}\left(r_{o} / r_{i}\right)}
$$

It is assumed that the region of the electric field under investigation is far away from any electrode edge, and that the suspension is sufficiently dilute to be considered as a pure fluid with the field not distorted by fluid motion. 
The above parameters facilitate particle trajectory calculations, assuming that a spherical particle is small enough to be considered as a point charge in an unperturbated electric field and of sufficient size for Stokes' law to apply, Newton's $2^{\text {nd }}$ law may be applied in the radial direction to give

$v_{p}=\frac{d r}{d t}=\frac{q E}{3 \pi \mu x_{a v}}-v_{r}$

where $v_{p}$ is the particle radial velocity. The particle charge $q$ is given by

$q=2 \pi \varepsilon_{0} D x_{a v} \zeta\left(1+0.5 K x_{a v}\right)$

where $\varepsilon_{o}$ is the permittivity of a vacuum, $D$ the fluid dielectric constant, $\zeta$ the zeta potential and $k^{-1}$ the electrical double layer thickness. It is assumed for present purposes that $\left(0.5 \kappa x_{a v}\right)<<1$ and that the particle is sufficiently small to be convected in the axial direction by the fluid motion. It is important to note that omitted from this analysis are the electrophoretic relaxation effects ${ }^{11}$ and the inertial or lift velocity caused by the fluid flow ${ }^{12}$. For the suspensions used in this work the magnitude of the latter is small compared to the electrical and drag induced velocities.

Equation (6) can be used in conjunction with the relevant fluid flow electric field profiles to give the particle position at any time during motion through an electroseparator. A similar analysis may be performed for particle motion through several other channel geometries.

Figure 2 shows the calculated trajectories of particles injected at different radii into fluid flowing axially along the annular section formed between two concentric cylinders. This represents a tubular geometry CFM which is similar to that used in the experimental work presented here. Particles introduced at radii close to the porous surface are rapidly pulled onto the septum. The application of a potential gradient enables the particles to remain in suspension for a greater distance by virtue of the induced electrophoretic velocity. If the field strength is sufficiently high, particles may be prevented from contacting the porous wall completely - a situation analogous to the application of the critical field strength. Although the results are specific to the flow conditions quoted, particles introduced part way across the annulus show no tendency to approach the porous surface. This appears to indicate that only those particles fed closer to the surface of the filter will create a fouling problem during crossflow microfiltration.

The influence of the electric field strength is also illustrated in Table 1 which shows the effect of both electrode and channel geometry. For the flow conditions quoted a particle introduced into the channel at a distance $0.5 \mathrm{~mm}$ from the porous wall is drawn onto the septum surface. With a tubular geometry and porous inner wall a particle remains in suspension for the greatest distance. When an electric field gradient is applied the difference between trajectories in the three filter types becomes more pronounced. The fluid flow profiles are essentially similar for the three geometries shown ${ }^{8}$ and the differences in particle trajectories are almost entirely attributable to the electric field strength generated at the porous surface. This indicates that for an electrically aided CFM the field strength generated at the septum surface is of prime importance, possibly dictating the membrane fouling rate. If a sufficiently high field gradient can be achieved then it may be possible to prevent particulate fouling completely.

The apparent importance of the electric field strength to the electrofiltration process led to detailed calculations ${ }^{8}$ of field strengths around other regular geometric electrodes, and around multitube bundles representative of a multitubular CFM. By employing electrodes of higher curvature it is 
possible to concentrate the electrical potential at various points in the space between the electrodes, leading to parts of the filter cross-section which experience correspondingly high field gradients. If it were possible to combine the location of a high curvature electrode with the separating surface of a CFM, then worthwhile improvements in separation efficiency may be achievable. Figures 3 and 4 show two alternative five tube arrays, one in a circular and the other in a square housing. Figure 3 shows a possible configuration for four filters each held at zero voltage, with a central electrode of the same diameter as each filter and the outer casing at $100 \mathrm{~V}$. The maximum field strength on any of the filtering surfaces is about $15 \mathrm{~V} \mathrm{~cm}^{-1}$, with much of the surface at a rather lower value. Reducing the filter diameter would lead to an increase of the field; an example of four such filters is shown in Figure 4 in a square casing. A greater part of the filter surface is then shown to be at $15 \mathrm{~V} \mathrm{~cm}^{-1}$. However, apart from engineering difficulties associated with manufacturing small diameter/high surface area membrane filters, a higher potential gradient at the filtering surface appears to be generally obtainable with a single filter tube configuration; for this equation (5) is applicable and example distributions are shown on Figure 5.

The solutions to Laplace's equation presented above are only valid provided the electrodes are considered to be of infinite length. If the electrodes have a finite length then 'edge effects' must be taken into account. At an electrode edge the potential gradient will decrease rapidly in an outward direction at a given rate. Although it is difficult to assign a true value to this rate of change in potential some indication of edge effects can be gained by assigning extreme values ${ }^{13}$. Shown in Figure 6 is the potential distribution between two parallel plate electrodes with $\mathrm{d} \varphi / \mathrm{d} x$ at the plate edge set at a high negative value. The effect of the electrode edge is to distort the potential distribution from the ideal and this is exaggerated when the plates are narrow. The potential is concentrated toward the plate having the higher potential. However, if the plates are of sufficient width then little or no disturbance occurs in the middle section of the electrodes. If $\mathrm{d} \varphi / \mathrm{d} x=0$ at the plate edge then a uniform potential distribution would exist between the plates with the field strength being constant across the section.

Thus, both electrode configuration and electrode size must be carefully considered in the design of an electrofilter. If the form of the electric field is not optimised then poor separation efficiencies may be produced. The theory presented above has been extended to produce a mathematical model capable of describing a crossflow microfilter ${ }^{8}$. Using the model it is possible to obtain an engineering appraisal of the effects of an applied electric field, and this highlights some of the most important operating parameters.

\section{EXPERIMENTAL RESULTS}

An experimental crossflow filter facility has been developed ${ }^{9}$ to allow investigations into effects of processing variables on the performance of an electrically assisted CFM. Apart from the geometric configuration of the filter assembly and processing variables such as crossflow velocity, feed concentration and voltage gradient, the state of the particle/solution interface is probably the most crucial factor when regarding performance success of an electrofilter. With this in mind the characteristics of various particulate systems have been investigated on a small scale deadend filter to facilitate estimation of limiting values for zeta potential and particle size. Suspension conductivities used varied between $10^{-4}$ and $2.5 \times 10^{-3} \mathrm{ohm}^{-1} \mathrm{~cm}^{-1}$, over which range there was little effect of this parameter; however, at very high conductivities difficulties with generating the necessary field and accommodating the Joule heating effects are likely to be severe and prevent useful application of the electrofiltration technique. 
The characteristics of the particles used in the experiments are shown on Table 2. Additionally, a few unsuccessful experiments were carried out with yeast (mean size $8.9 \mu \mathrm{m}$ ). The separability of bentonite, anatase, china clay and rutile was enhanced using electrical assistance. The electrophoretic mobility of aragonite was too low compared with the hydrodynamically induced velocity of the particle towards the filtering septum to prevent motion of the particles in that direction. Experiments with $\mathrm{CBL}$, talc and calcite indicated no improvement in filter performance when electrical fields were applied. The results imply that electrical assistance in CFM is unlikely to be effective on particles larger than about 6-8 $\mu \mathrm{m}$ or when the zeta potential is smaller than about $25 \mathrm{mV}$. These values appear quite reasonable noting, from equation (6), that the electrophoretic mobility is then of the same order as the radial fluid velocity at the surface. Putting $\varepsilon_{0}=8.854 \times 10^{-12} \mathrm{C}^{2} \mathrm{~J}^{-1} \mathrm{~m}^{-1}, D=80, \zeta$ $=25 \mathrm{mV}, E=100 \mathrm{~V} \mathrm{~cm}^{-1}$ and $\mu=10^{-3} \mathrm{~kg} \mathrm{~m}^{-1} \mathrm{~s}^{-1}$ gives the electrophoretic velocity as $0.12 \mathrm{~mm} \mathrm{~s}^{-1}$, compared with a typical permeate velocity of 0.1 to $0.6 \mathrm{~mm} \mathrm{~s}^{-1}$ normal to the filtering surface.

Figure 7 shows the typical effect of increasing the electric field strength on the permeate flux. For the filtration of a $0.04 \% \mathrm{v} / \mathrm{v}$ china clay suspension the filtrate flux falls rapidly initially, with the flux decline attributable to particle deposition at the membrane surface ${ }^{14}$. When an electric field is applied the rate at which membrane fouling occurs is reduced. Figure 8 shows a similar effect to this for the filtration of a relatively high solids content china clay suspension. For the increased slurry concentration and no applied field the permeate rate falls more rapidly. The application of the electric field increases the filtrate flux with this becoming more pronounced as filtration proceeds. Moreover, it appears that particles previously deposited upon the membrane (during the filtration) are re-entrained into the crossflow stream after a given time, with a subsequent increase in permeate flux. This is probably due to the hydrodynamic drag force holding the particles at the surface of the deposit falling to such a level that it is smaller than the combined shear and electrophoretic effects. If this reasoning is correct then flux should vary cyclically with time ${ }^{15}$. The flux curves on Figure 7 are approaching an equilibrium after an initial fall, at which a near constant separation rate is rapidly achieved and there is little or no further net fouling of the membrane surface. When the electric field is applied the permeate rate is increased to a higher level. The results are specific to the experimental conditions quoted and it appears that particle polarisation is a prominent cause of membrane fouling. The fouling can be controlled by a combination of the applied electric field and the scouring action of the crossflow stream. Similar experimental results to those shown above have been obtained for many other suspensions ${ }^{8}$.

It has already been shown that the optimisation of the electrode geometry employed within an electroseparator can help the separation efficiency and reduce electrical power consumption. Figure 9 indicates that it may be possible to further reduce power consumption by pulsing the electric field. The pulsing was achieved by switching the applied potential on and off at regular intervals; when separation was initiated the power was on. The pulsed field produces filtration fluxes higher than that attainable with a constant applied potential and an equilibrium (RMS) separation rate may be attained when operating conditions allow. The surges in filtrate flux are probably due to electroosmosis rather than electrophoresis with the electrofiltration process aided by reduced gas formation at the electrode surfaces, a further contributory factor may be a modification to suspension viscosity in the vicinity of the membrane surface.

\section{CONCLUSIONS}

The separation of fine particle suspensions by microfiltration can be difficult to achieve in practice due to membrane fouling. The application of DC electric fields can prevent much of this fouling and facilitate the maintenance of a high filtrate flux. This is achieved by a combination of electrokinetic effects. The optimisation of the electrode geometry can reduce the power consumption required to 
generate a given potential gradient within an electric field. It is also sometimes possible to produce flux improvements by pulsing the applied potential; this will further reduce the electrical power consumption. The theoretical analysis has shown that potential gradient produced at the membrane surface is important where prevention of particle deposition is required.

\section{NOMENCLATURE}

$\mathrm{d} p / \mathrm{dz}$ pressure gradient in the axial direction $\left(\mathrm{N} \mathrm{m}^{-3}\right)$

$D \quad$ dielectric constant of a particle

E electric field strength $\left(\mathrm{V} \mathrm{cm}^{-1}\right)$

$g$ acceleration due to gravity $\left(\mathrm{m} \mathrm{s}^{-2}\right)$

$h \quad$ electrode separation/width annular flow space $(\mathrm{m})$

$L \quad$ length $(\mathrm{m})$

$q$ particle surface charge (C)

$r \quad$ radial coordinate $(\mathrm{m})$

$r_{\text {ent }} \quad$ particle entry radius $(\mathrm{m})$

$r_{i} \quad$ radius of inner electrode $(\mathrm{m})$

$r_{o} \quad$ radius of outer electrode $(\mathrm{m})$

$t \quad$ time (s)

$v_{o} \quad$ crossflow velocity $\left(\mathrm{m} \mathrm{s}^{-1}\right)$

$v_{p} \quad$ particle velocity $\left(\mathrm{m} \mathrm{s}^{-1}\right)$

$v_{r} \quad$ radial velocity of the fluid flow $\left(\mathrm{m} \mathrm{s}^{-1}\right)$

$v_{w} \quad$ permeate flux $\left(\mathrm{m}^{3} \mathrm{~m}^{-2} \mathrm{~s}^{-1}\right)$

$v_{z} \quad$ axial velocity of the fluid flow $\left(\mathrm{m} \mathrm{s}^{-1}\right)$

$x_{a v} \quad$ average particle diameter $(\mathrm{m})$

$x, y \quad$ Cartesian coordinate directions $(\mathrm{m})$

$z \quad$ axial coordinate $(\mathrm{m})$

$\varepsilon_{0} \quad$ permittivity of a vacuum $\left(\mathrm{C}^{2} \mathrm{~J}^{-1} \mathrm{~m}^{-1}\right)$

$\zeta \quad$ zeta potential $(\mathrm{V})$

$1 / k \quad$ thickness of the electric double layer $(\mathrm{m})$

$\mu \quad$ dynamic viscosity of the fluid $\left(\mathrm{N} \mathrm{s} \mathrm{m}^{-2}\right)$

$v \quad$ kinematic viscosity of the fluid $\left(\mathrm{m}^{2} \mathrm{~s}^{-1}\right)$

$\rho \quad$ density of the fluid $\left(\mathrm{kg} \mathrm{m}^{-3}\right)$

$\varphi \quad$ electric potential (V)

$\varphi_{i} \quad$ electric potential at the inner electrode $(V)$

$\varphi_{0} \quad$ electric potential at the outer electrode $(\mathrm{V})$

\section{REFERENCES}

1. Fane A.G., in Progress in Filtration and Separation, Vol. 4, Wakeman R.J. (Ed.), Elsevier, Amsterdam, 1986.

2. Yukawa H., Kobayashi K., Toshida H. and Iwata M., in Progress in Filtration and Separation, Vol. 1, Wakeman R.J. (Ed.), Elsevier, Amsterdam, 1979.

3. Moulik S.P., Env. Sci. Technol., 5, 771, 1971.

4. Wakeman R.J., Filtration and Separation, 9, 316, 1982.

Cite paper as: Wakeman R.J. and Tarleton E.S., 1987, Membrane fouling prevention in crossflow microfiltration by the use of electric fields Chemical Engineering Science, 42(4), 829-842. DOI: 10.1016/0009-2509(87)80042-8 
5. Henry J.D., Lawler L.F. and Alex Kuo C.H., A/ChEJ, 23, 851, 1977.

6. Lee C.H., Gidaspow D. and Wasan D.T., Ind. Eng. Chem. Fundam., 19, 166, 1980.

7. Mikhlin J.A., Webster M.E. and Turkson A.K., J. Separ. Proc. Technol., 3, 16, 1982.

8. Tarleton E.S., A study of electrically assisted microfiltration, PhD Thesis, University of Exeter, 1986.

9. Wakeman R.J. and Tarleton E.S., Filtration and Separation, 23, 174, 1986.

10. Wakeman R.J. and Tarleton E.S., Proc. $4^{\text {th }}$ World Filtration Congress, Ostend, Belgium, 22-25 April 1986.

11. Kortium G., Treatise on Electrochemistry, Elsevier, Amsterdam, 1965.

12. Altena F.W. and Belfort G., Chem. Eng. Sci., 2, 343, 1984.

13. Gerald C.F. and Wheatley P.O., Applied Numerical Analysis, Adison-Wesley, Reading, Massachusetts, 1984.

14. Bertera R.G., Metcalfe M.G. and Steven J.-H., Paper presented to IChemE Yorkshire/Northwest Branches and Filtration Society, Leeds, Yorkshire, April 1984.

15. Wakeman R.J., The Chemical Engineer, 426, 65, 1986.

\section{ACKNOWLEDGEMENT}

The authors wish to record their gratitude for receipt of a Science and Engineering Research Council grant in support of this work. The grant was awarded under the auspices of the Specially Promoted Programme in Particulate Technology. 
FIGURES AND TABLES
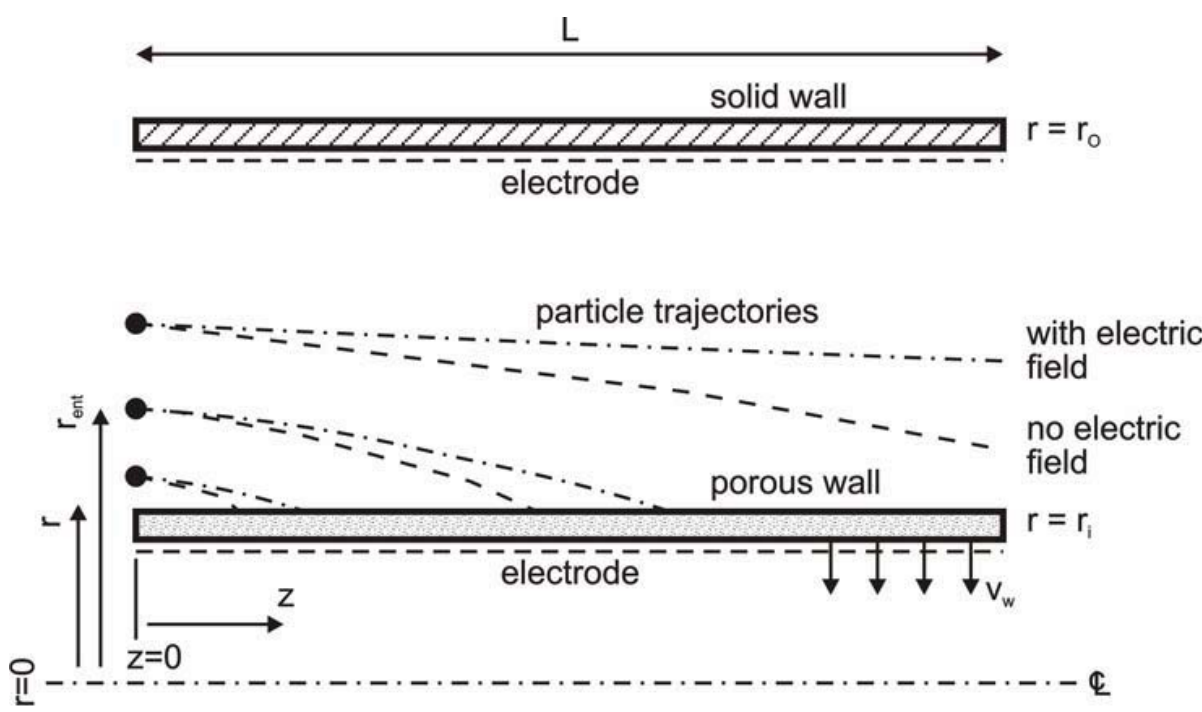

Figure 1: Schematic diagram of particle and liquid flows between solid and porous walls.

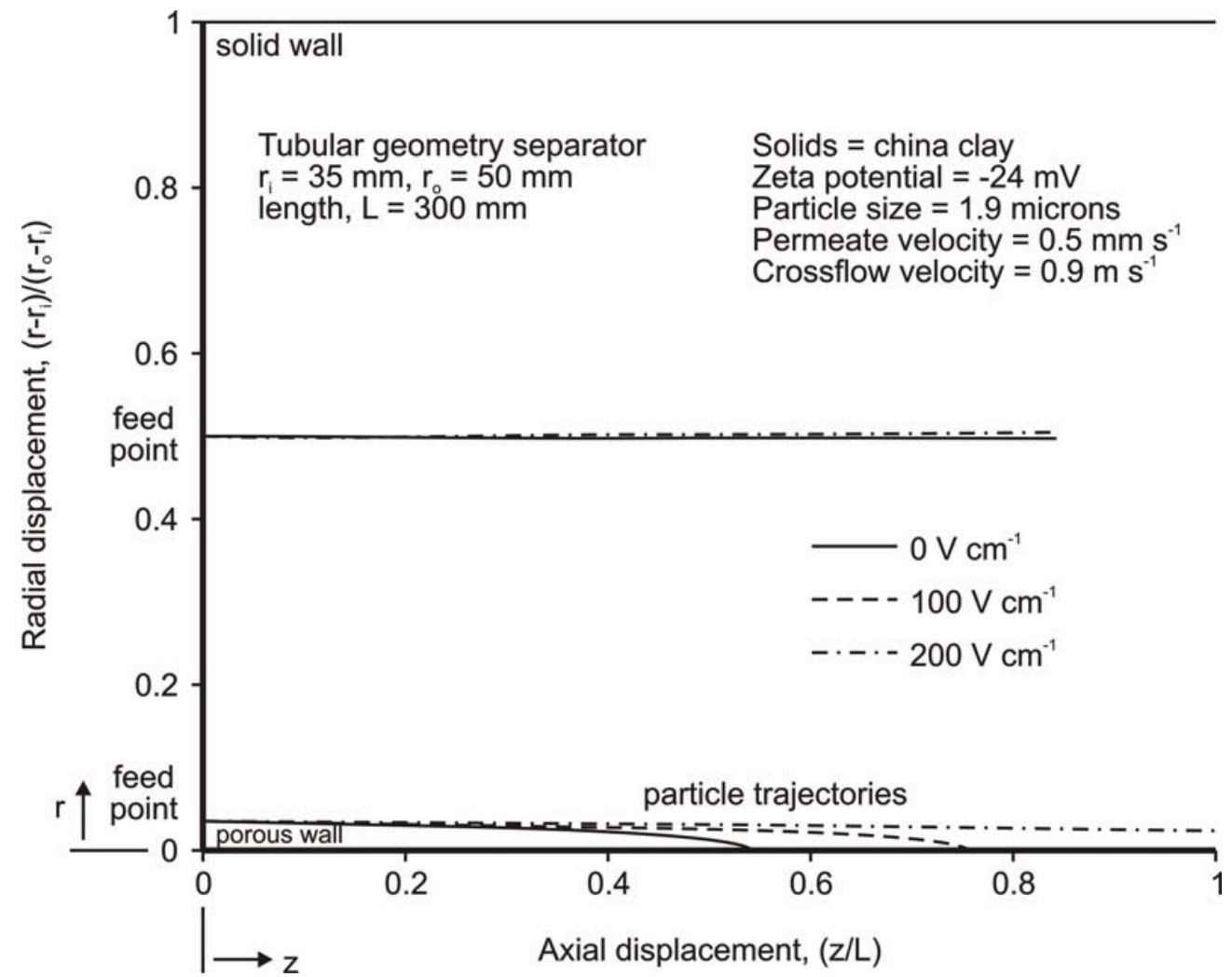

Figure 2: Effect of electric field strength on particle trajectory. 


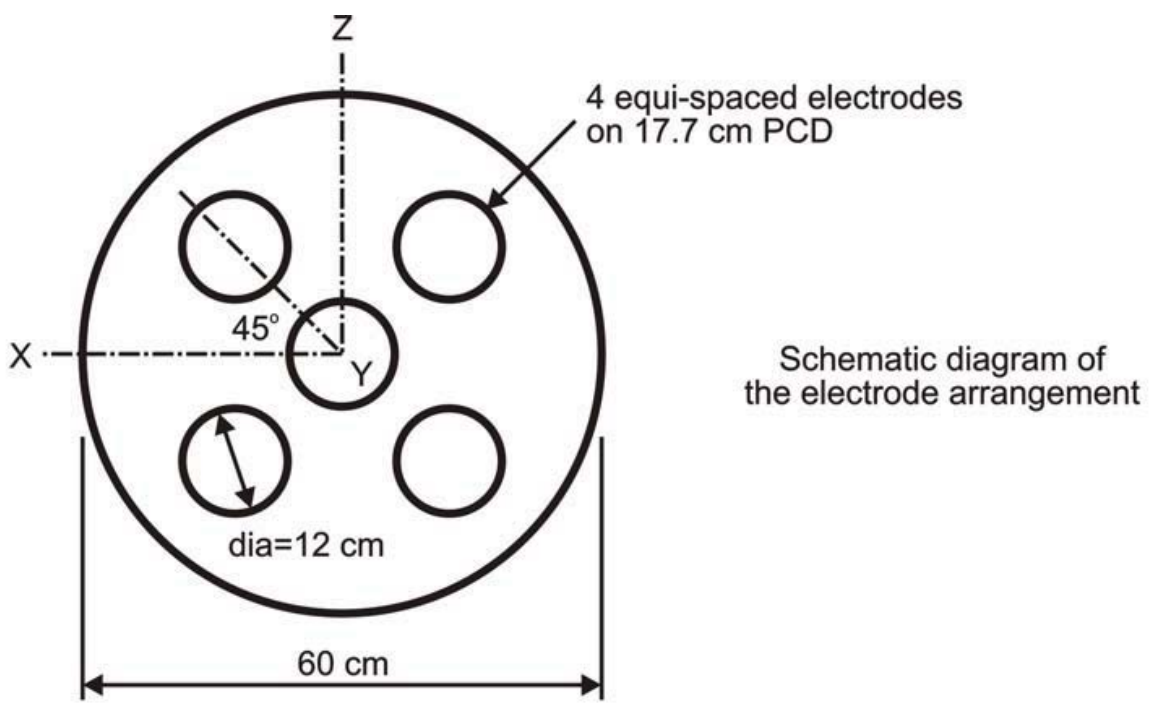

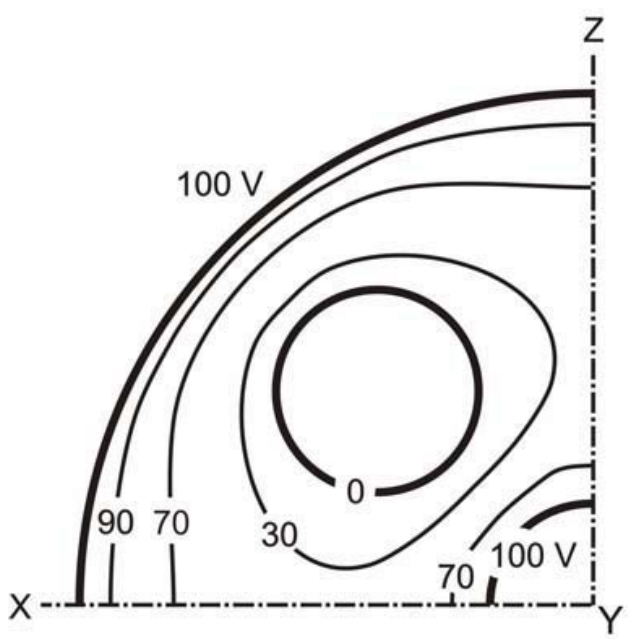

Potential distribution for the application of $100 \mathrm{~V}$

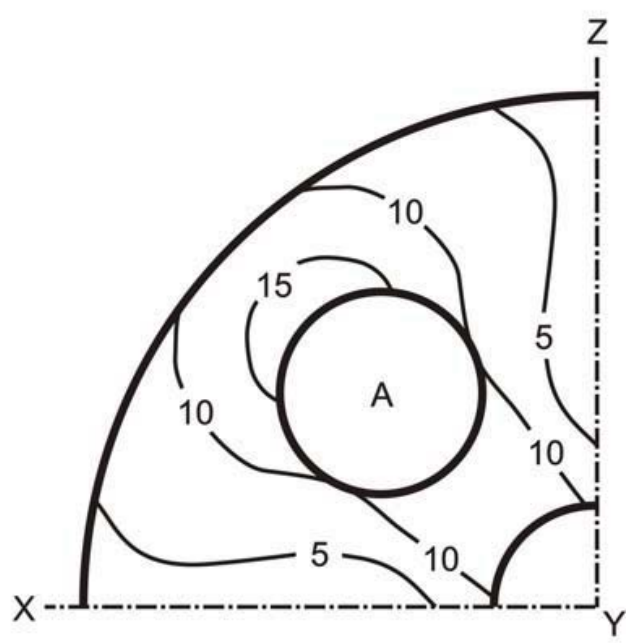

Field strength distribution $\left(\mathrm{V} \mathrm{cm}^{-1}\right)$ (field gradients measured normal to the surface of electrode ' $A$ ')

Figure 3: Potential distribution around multitube filter/electrode arrangement. 


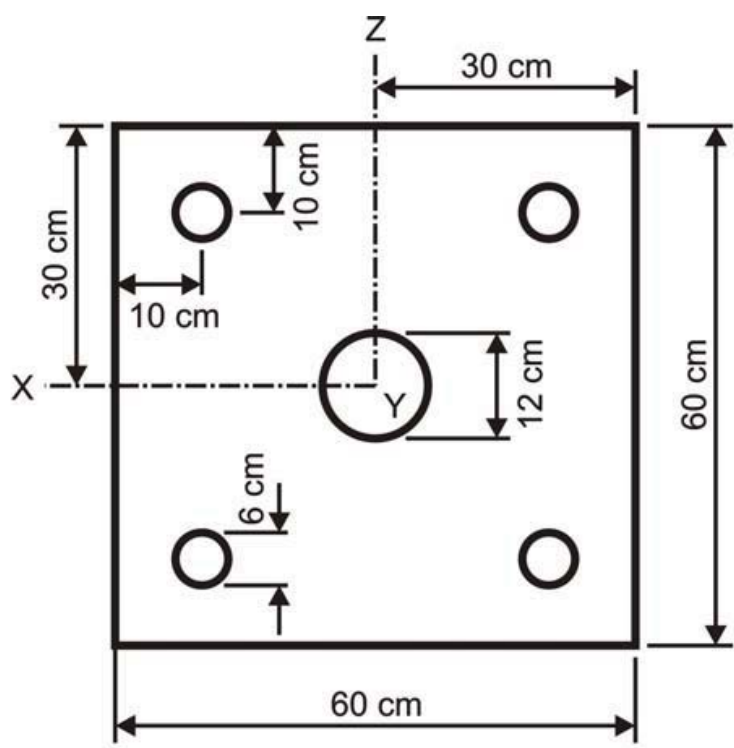

Schematic diagram of the electrode arrangement

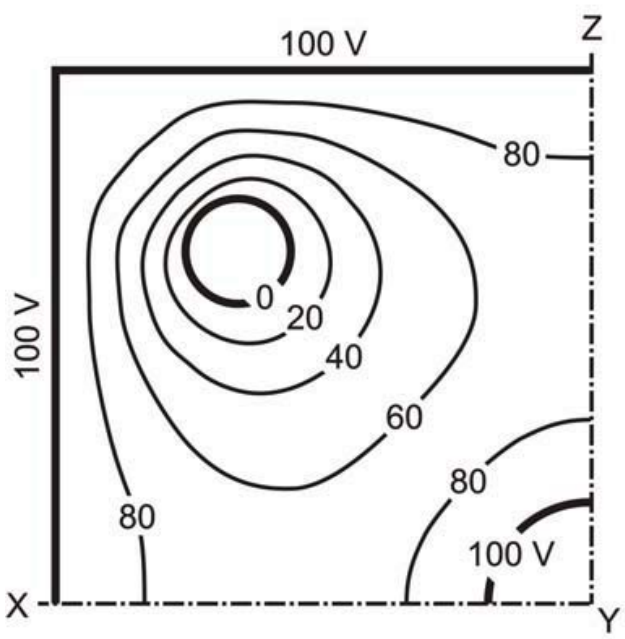

Potential distribution for the application of $100 \mathrm{~V}$

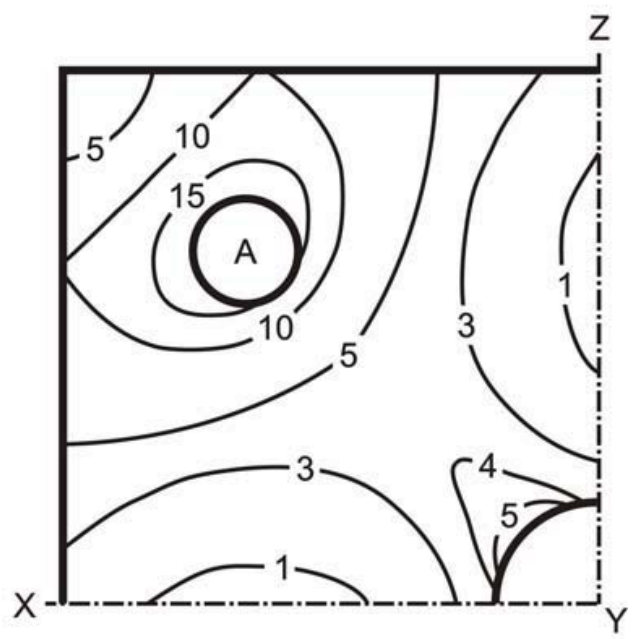

Field strength distribution $\left(\mathrm{V} \mathrm{cm}^{-1}\right)$ (field gradients measured normal to the surface of electrode ' $A$ ')

Figure 4: Potential distribution around multitube filter/electrode arrangement. 


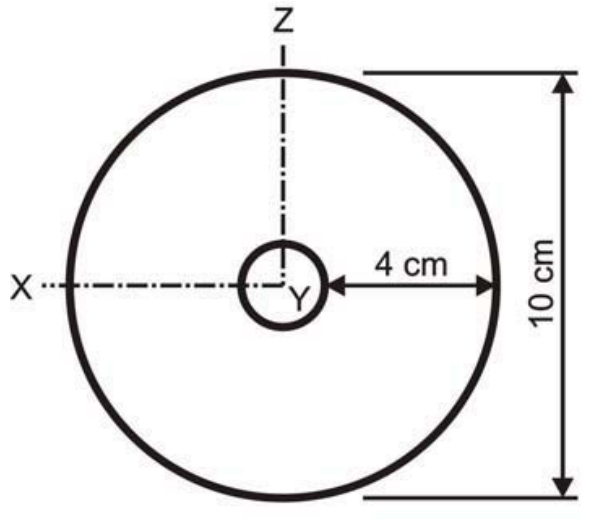

Schematic diagram of the electrode arrangement

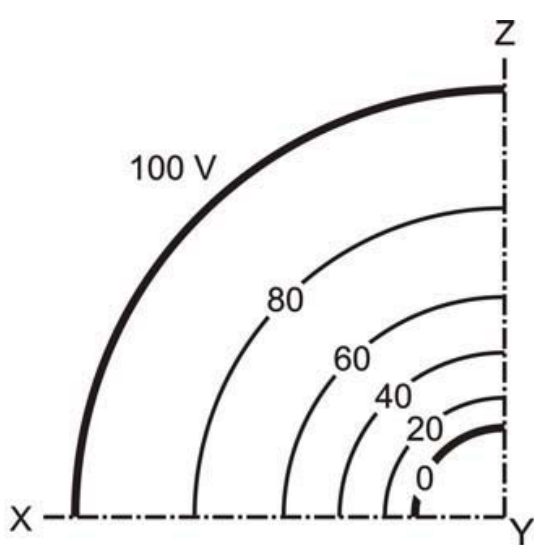

Potential distribution with the application of $100 \mathrm{~V}$ to the outer electrode

\section{POTENTIAL GRADIENT DISTRIBUTION ON X-Y}

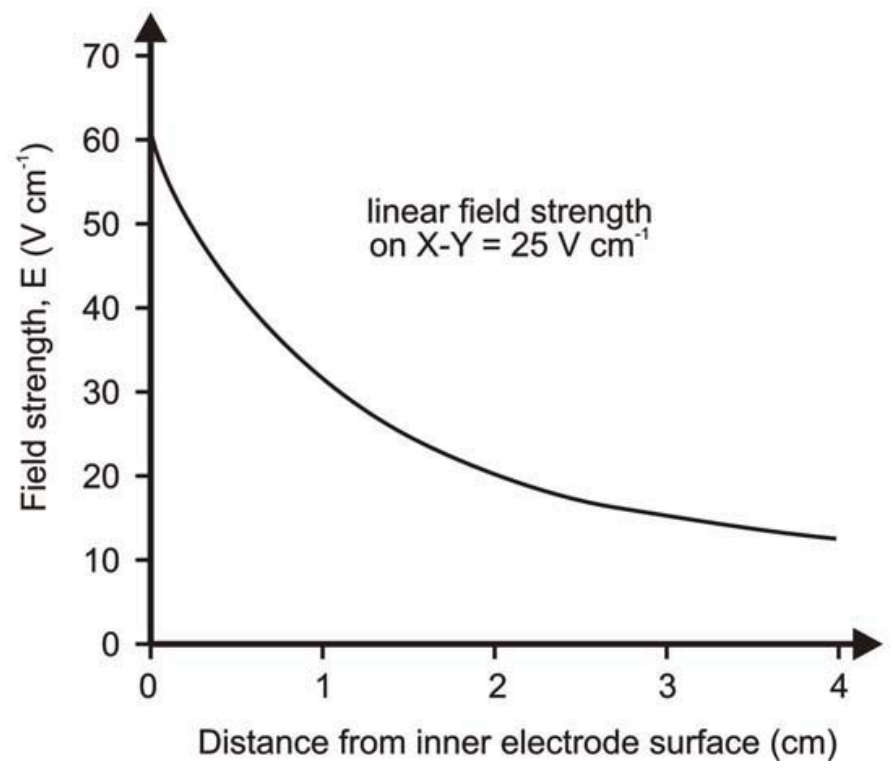

Figure 5: Potential distribution between two concentric circular cylinders. 

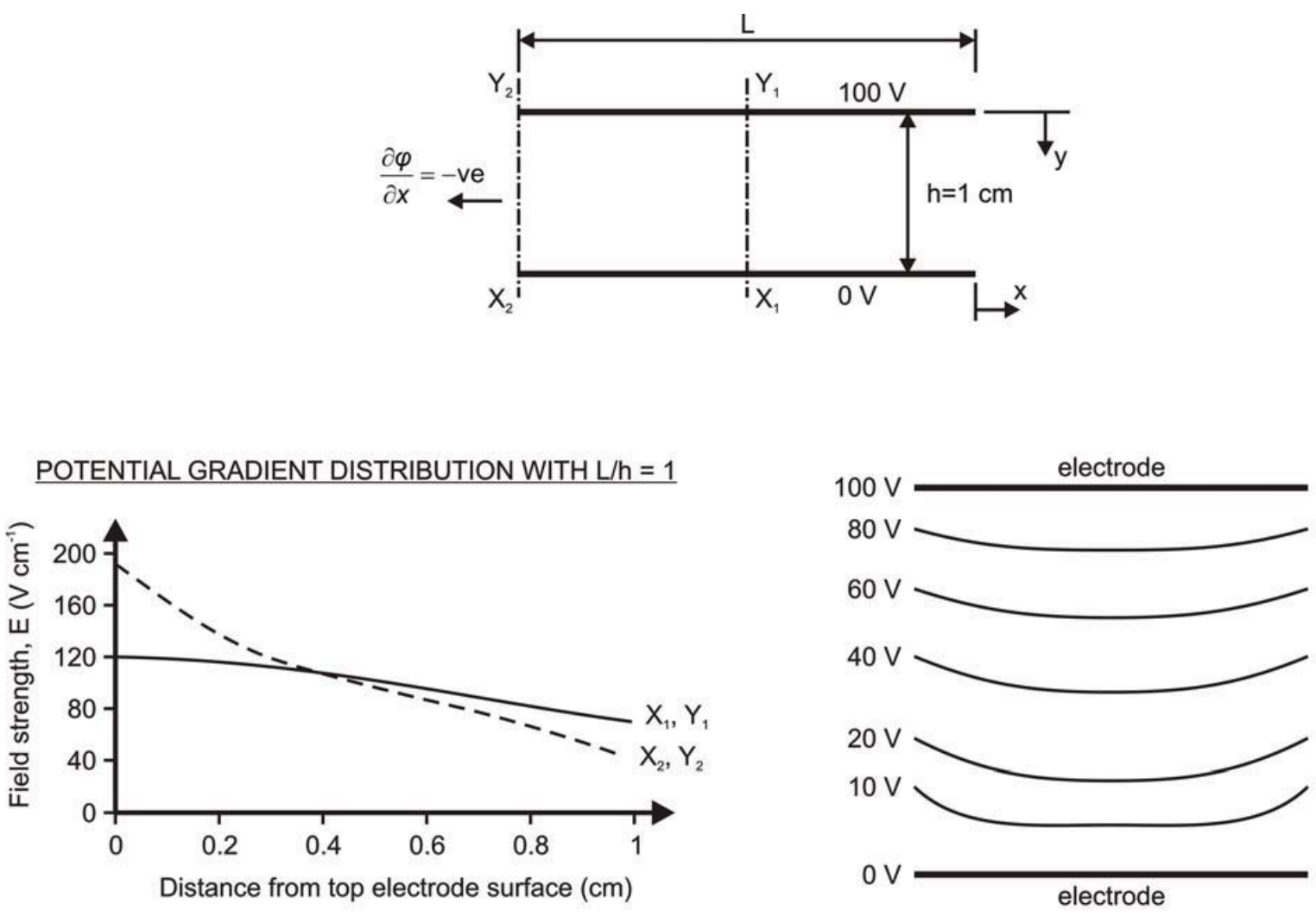

\section{POTENTIAL GRADIENT DISTRIBUTION WITH L/h $=4$}
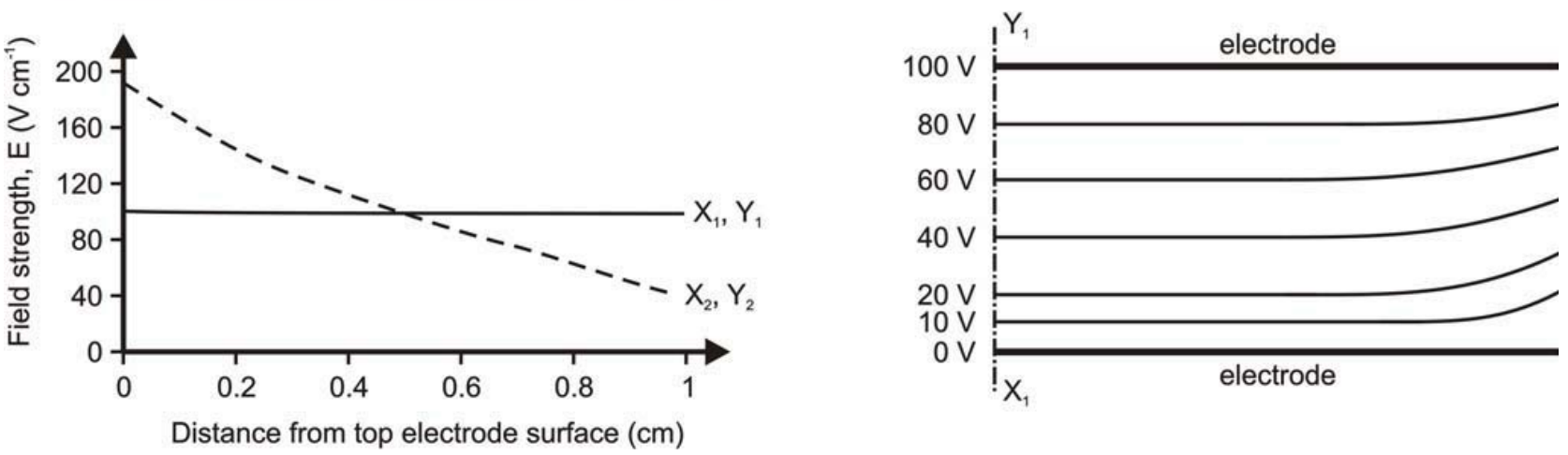

Figure 6: Potential distribution between two parallel plate electrodes (with edge effects). 


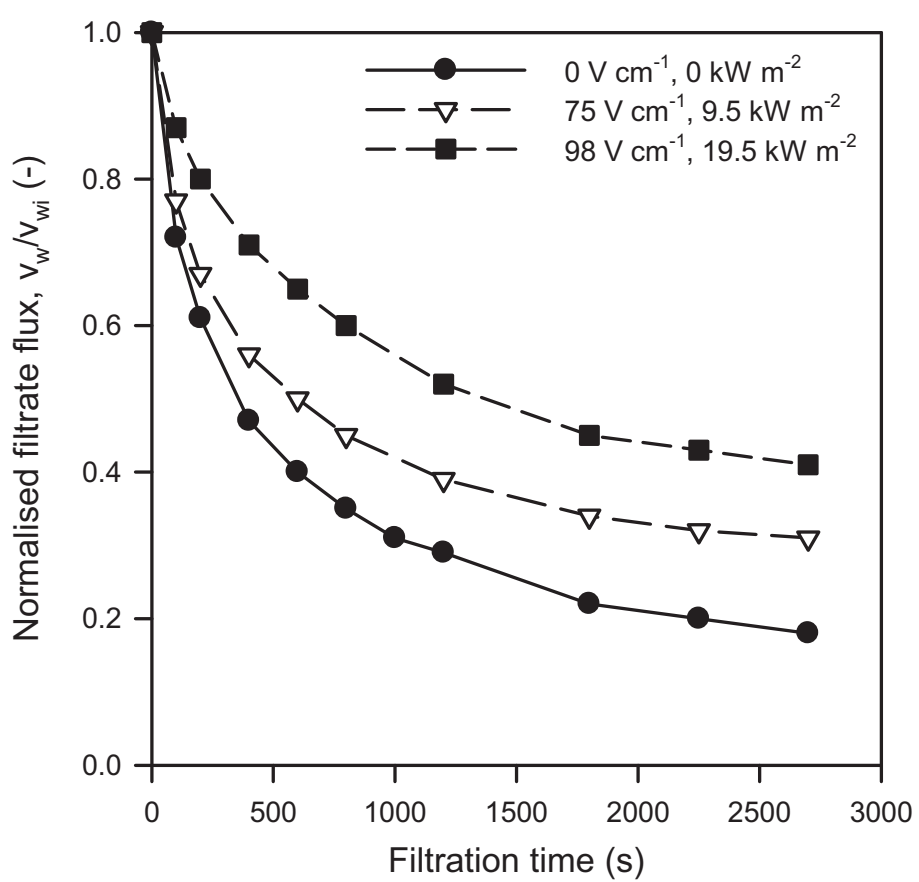

Figure 7: Crossflow filter tests for $0.04 \% \mathrm{v} / \mathrm{v}$ china suspension. Crossflow velocity $=0.9 \mathrm{~m} \mathrm{~s}^{-1}$; Initial filtration rate $=2.2 \mathrm{~m}^{3} \mathrm{~m}^{-2} \mathrm{~h}^{-1}$; Suspension conductivity $=1.429 \times 10^{-4} \mathrm{ohm}^{-1} \mathrm{~cm}^{-1}$; Electrode separation $=$ $4 \mathrm{~cm}$.

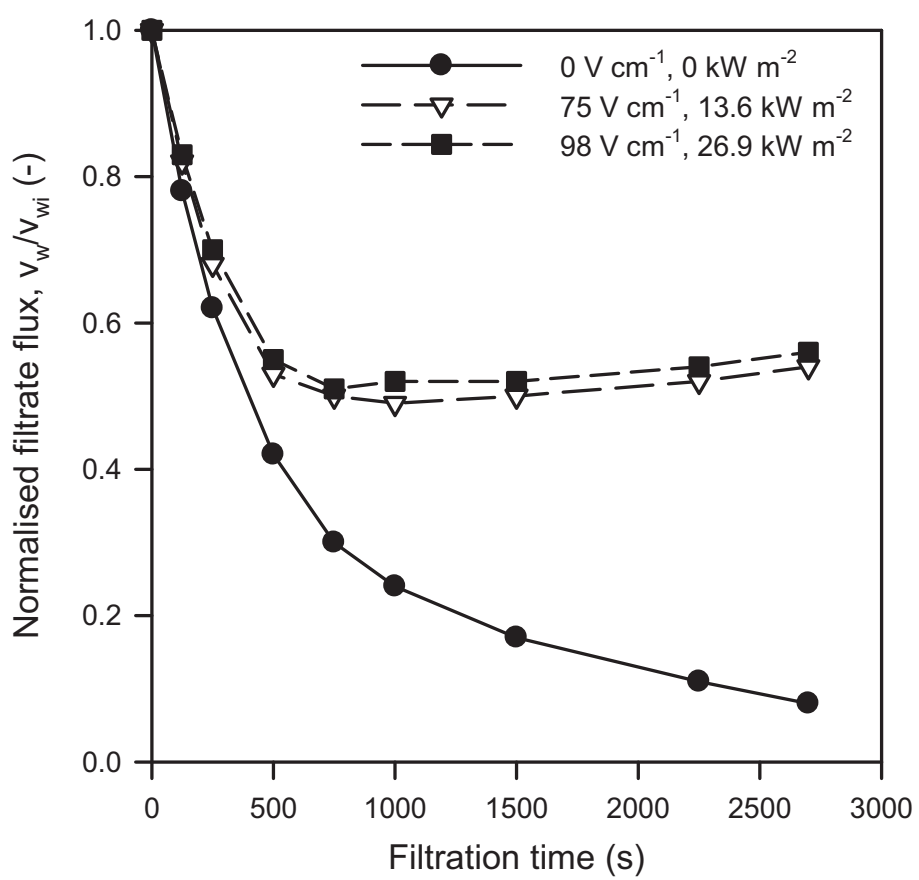

Figure 8: Crossflow filter tests for $0.68 \% \mathrm{v} / \mathrm{v}$ china clay suspension. Crossflow velocity $=0.9 \mathrm{~m} \mathrm{~s}^{-1}$; Initial filtration rate $=0.64 \mathrm{~m}^{3} \mathrm{~m}^{-2} \mathrm{~h}^{-1}$; Suspension conductivity $=1.439 \times 10^{-4} \mathrm{ohm}^{-1} \mathrm{~cm}^{-1}$; Electrode separation $=4 \mathrm{~cm}$. 


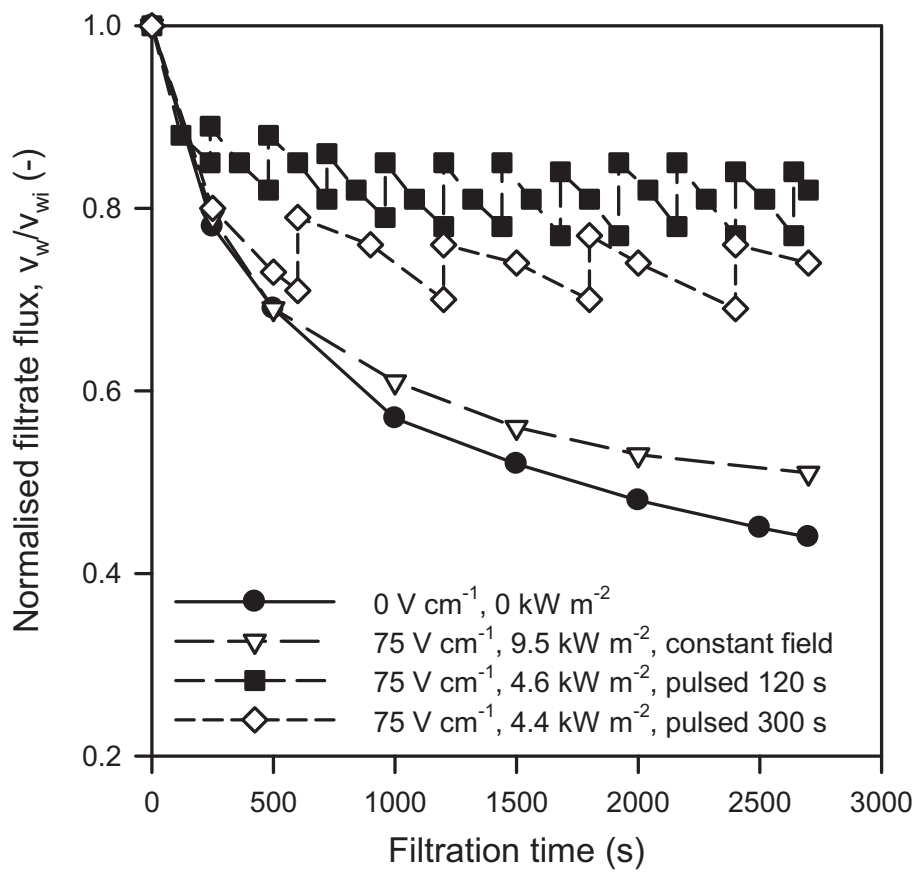

Figure 9: Crossflow filter tests for $0.0085 \% \mathrm{v} / \mathrm{v}$ anatase suspension using pulsed electric fields. Crossflow velocity $=0.9 \mathrm{~m} \mathrm{~s}^{-1}$; Initial filtration rate $=2.1 \mathrm{~m}^{3} \mathrm{~m}^{-2} \mathrm{~h}^{-1}$; Suspension conductivity $=1.43 \times 10^{-4}$ $\mathrm{ohm}^{-1} \mathrm{~cm}^{-1}$; Electrode separation $=4 \mathrm{~cm}$; 


\begin{tabular}{|c|c|c|c|}
\hline \multirow{2}{*}{$\begin{array}{c}\text { Electric field } \\
\text { strength }\left(\mathrm{V} \mathrm{cm}^{-1}\right)\end{array}$} & \multicolumn{3}{|c|}{ Axial distance travelled before particle impinges upon the septum } \\
& $\begin{array}{c}\text { Surface, } \mathrm{z} / \mathrm{L} \\
\text { Tubular geometry, } \\
\text { porous inner wall }\end{array}$ & $\begin{array}{c}\text { Tubular geometry, } \\
\text { porous outer wall }\end{array}$ & Planar geometry \\
\hline 0 & 0.537 & 0.525 & 0.528 \\
50 & 0.626 & 0.583 & 0.598 \\
100 & 0.751 & 0.656 & 0.692 \\
150 & 0.942 & 0.751 & 0.822 \\
\hline
\end{tabular}

Flow conditions: $x_{a v}=1.92 \mu \mathrm{m} ; \zeta=-24 \mathrm{mV} ; v_{w}=0.5 \mathrm{~mm} \mathrm{~s}^{-1} ; v_{o}=0.9 \mathrm{~m} \mathrm{~s}^{-1} ; r_{i}=0.035 \mathrm{~m}$; $r_{0}=0.05 \mathrm{~m} ; h=0.015 \mathrm{~m} ; L=0.3 \mathrm{~m}$

Table 1: Capture positions of particles entering the separator $0.05 \mathrm{~mm}$ from the septum surface.

\begin{tabular}{|l|c|c|c|c|c|}
\hline Material & $\begin{array}{c}\text { Mean size } \\
(\mu \mathrm{m})\end{array}$ & $\begin{array}{c}\text { Variance } \\
\left(\mu \mathrm{m}^{2}\right)\end{array}$ & $\begin{array}{c}\text { Density } \\
\left(\mathrm{kg} \mathrm{m}^{-3}\right)\end{array}$ & $\mathrm{pH}$ & $\begin{array}{c}\zeta \text {-potential } \\
(\mathrm{mV})\end{array}$ \\
\hline Bentonite & 2.6 & 4.3 & 2320 & - & - \\
Anatase & 3.3 & 2.6 & 3900 & 6.1 & -58 \\
China clay & 3.7 & 19.1 & 2570 & 3.9 & -24 \\
Rutile & 8.1 & 60.6 & 4100 & 6.2 & $(-95)$ \\
Aragonite & 9.3 & 10.9 & 2875 & 8.1 & +0.21 \\
CBL & 9.6 & 62.2 & 2180 & 7.8 & -30 \\
(diatomaceous earth) & & & & & \\
Talc & 14.4 & 78.8 & 2790 & 9 & -25 \\
Calcite & 17.3 & 27.7 & 2650 & 9.5 & +25 \\
\hline
\end{tabular}

Table 2: Properties of particles used in experimental work. 